Research Paper

\title{
Increased tumor-infiltrating plasmacytoid dendritic cells promote cancer cell proliferation and invasion via TNF- $\alpha /$ NF-KB/CXCR-4 pathway in oral squamous cell carcinoma
}

\author{
Nannan Han ${ }^{1,2^{*}}$, Xing $\mathrm{Li}^{3^{*}}$, Yupu Wang1,2, Lin Wang1,2, Chunye Zhang ${ }^{2,4}$, Zun Zhang ${ }^{5^{\bowtie}}$, Min Ruan ${ }^{1,2}$, \\ Chenping Zhang ${ }^{1,2}$ \\ 1. Department of Oral Maxillofacial-Head and Neck Oncology, Shanghai Ninth People's Hospital, College of Stomatology, Shanghai Jiao Tong University School of \\ Medicine, Shanghai, 200011, China. \\ 2. Shanghai Key Laboratory of Stomatology, Shanghai Research Institute of Stomatology, National Clinical Research Center for Oral Diseases, Shanghai, 200011, China. \\ 3. Department of Dentistry, Affiliated Hospital, Weifang Medical University, Weifang, 261031, China. \\ 4. Department of Oral Pathology, Shanghai Ninth People's Hospital, College of Stomatology, Shanghai Jiao Tong University School of Medicine, Shanghai, 200011, China. \\ 5. Department of Stomatology, Shanghai East Hospital, Tongji University. Shanghai 200120, China. \\ *These authors contributed equally to this work. \\ $\triangle$ Corresponding authors: Zun Zhang, Department of Stomatology, Shanghai East Hospital, Tongji University, 150 Jimo Road, Pudong District, Shanghai 200011, China. \\ E-mail: doctorzhangzun@126.com; Phone:+86-21-38804518; Min Ruan, Department of Oral Maxillofacial-Head and Neck Oncology, Shanghai Ninth People's Hospital, \\ College of Stomatology, Shanghai Jiao Tong University School of Medicine, No 639, Zhizaoju Rd, Shanghai, 200011, China. E-mail: doctorruanmin@sjtu.edu.cn; Phone: \\ +86-18717893527.
}

(C) The author(s). This is an open access article distributed under the terms of the Creative Commons Attribution License (https://creativecommons.org/licenses/by/4.0/). See http://ivyspring.com/terms for full terms and conditions.

Received: 2020.11.07; Accepted: 2021.02.28; Published: 2021.03.19

\begin{abstract}
Background: Tumor-infiltrating immune cells are closely associated with tumor occurrence and progression. The present study explored the potential mechanism of tumor-infiltrating plasmacytoid dendritic cells (pDC) mediating the proliferation and metastasis of cancer cells in oral squamous cell carcinoma (OSCC).

Methods: PDC distribution was detected by immunofluorescence and flow cytometry. chemotaxis cytokine receptor-4/7 (CXCR-4/7) expression was detected by quantitative polymerase chain reaction and immunohistochemistry. Cell proliferation and migration were measured by CCK-8, colony formation, wound healing and transwell assay. ELISA and western blotting were used to investigate cytokines secretion and NF-KB pathway activity.

Results: Tumor-infiltrating PDC in OSCC was significantly increased and associated with tumor size, lymph node $(\mathrm{LN})$ metastasis $(P<0.05)$. Tumor-infiltrating-pDC-conditioned medium from OSCC patients significantly promoted tumor cell proliferation and invasion, which was at least partly mediated via enhancing the CXCR-4 expression of tumor cell. In addition, the activation of NF-KB pathway played a decisive role in the overexpression of CXCR-4, which was further regulated by PDC-derived TNF- $\alpha$ secretion.

Conclusions: Tumor-infiltrating PDC promoted oral cancer proliferation and invasion via activating the TNF- $\alpha$ /NF-KB/CXCR-4 pathway, which may serve as a potential immunological target for the treatment of OSCC in the future.
\end{abstract}

Key words: oral squamous cell carcinoma (OSCC); plasmacytoid dendritic cells (pDCs); lymph node metastasis; nuclear factor-kB (NF-kB); chemotaxis cytokine receptor-4 (CXCR-4)

\section{Introduction}

Oral squamous cell carcinoma (OSCC) is the most frequent histological type of head and neck cancer and the sixth most frequent malignancy across the world, with over 800,000 newly diagnosed cases and 166,000 people dying each year [1,2]. Despite new therapeutic modalities being introduced over the past two decades, the overall 5-year survival rate for
OSCC remains only approximately $60 \%$, highlighting the urgent need to identify new approaches for the prevention and treatment of OSCC $[2,3]$. In recent years, much attention has been directed toward tumor immunology research, with a particular focus on tumor-infiltrating immune cells $[4,5]$.

Tumor-infiltrating immune cells gather in the tumor microenvironment, accompanying cancer 
occurrence and progression [6]. Growing evidence suggests that the complex function of these cells is important in explaining the development, growth, and metastasis of cancer, besides the features of cancer cells themselves [7, 8]. However, in the past decades, the major research focus regarding tumorinfiltrating immune cells has been the tumorinfiltrating lymphocytes, including $\mathrm{CD}^{+} \mathrm{T}$ cells, $\mathrm{CD}^{+}$ $\mathrm{T}$ cells, and regulatory $\mathrm{T}$ cells, while the role of antigen-presenting cells, such as myeloid dendritic cells (mDC) and plasmacytoid dendritic cells (pDC), has not been widely explored [9-11].

$\mathrm{mDC}$ and $\mathrm{pDC}$ are two of the main professional antigen-presenting cells and play a critical, decisive role in determining the outcome of the immune response to antigens [12]. Recent studies suggest that pDC, specifically, are rather important in cancer immunity as these cells have been identified in many solid malignant tumors, including those of head and neck, breast, ovarian, and lung cancers [13, 14]. Unfortunately, pDC recruited to the tumor microenvironment often displays a non-activated state and is associated with tumor progression [15]. Further, in breast tumors, infiltration of $\mathrm{pDC}$ in the primary lesion was found to be correlated with adverse outcomes [16, 17]; while in ovarian cancer, the presence of $\mathrm{pDC}$ was not only associated with a poor clinical outcome but also served as a predictor of early relapse [18].

Previously, we also demonstrated an increased frequency of tumor-infiltrating $\mathrm{pDC}$ in the primary OSCC microenvironment [19]. Further molecular investigation showed that oral cancer cells could down-regulate TLR-9-mediated interferon- $\alpha$ (IFN- $\alpha$ ) production in $\mathrm{pDC}$ via increasing TGF- $\beta$ and IL-10 secretion, which may lead to severe functional impairment of these infiltrated pDC [20]. In addition, our clinicopathologic analysis revealed that an increased number of tumor-infiltrating $\mathrm{pDC}$ has a tendency to correlate with LN metastasis $(p<0.05)$, suggesting that these impaired $\mathrm{pDC}$ may facilitate cancer cells migration and invasion [19]; however, the underlying molecular mechanism remains unknown. The aim of this study sought to clarify the potential mechanism by which pDC mediated cancer cell proliferation and lymph node metastasis in oral squamous cell carcinoma.

\section{Methods}

\section{Patients and samples}

A total of 122 patients with primary OSCC treated between January 2014 and November 2014 in the Department of Oral Maxillofacial-Head and Neck Oncology, Ninth People's Hospital, Shanghai Jiao
Tong University School of Medicine, were enrolled. Patients fulfilling the following criteria were included in the study: (1) primary OSCC confirmed by pathology after surgery; (2) no radiotherapy, chemotherapy, or immunotherapy before surgery; and (3) complete clinicopathological data available. Paraffin-embedded tumor tissue sections prepared for immunohistochemistry of CD123.

Subsequently, from January 2018 to July 2018, we collected an additional 60 tumor tissue samples from OSCC patients that met the above criteria. Six patients (three males and three females, mean age of 57.2 years old) who underwent alveoloplasty were selected as controls. The collected tumor samples and normal oral mucosal epithelium were quickly washed in phosphate-buffered saline (PBS) thrice and divided into three portions, one of which was soaked in formalin, another was soaked in high-glucose Dulbecco's Modified Eagle Medium (DMEM; Gibco, Invitrogen, Carlsbad, USA) supplemented with $10 \%$ fetal bovine serum (FBS; Biowest, France) and the last was immediately frozen in liquid nitrogen and stored at $-80{ }^{\circ} \mathrm{C}$ for further analysis. No significant differences were noted in age, gender, alcohol use, or smoking habits between the control and OSCC groups. This study was approved by the Shanghai Ninth People's Hospital IRB and informed signed consent was obtained from each patient.

\section{Single-cell suspension preparation}

Surgical human primary OSCC tissue samples were washed several times with PBS and carefully minced to small pieces in sterile serum-free high-glucose DMEM (supplemented with $100 \mathrm{U} / \mathrm{mL}$ penicillin, $1 \mathrm{mM}$ glutamine, and $100 \mathrm{U} / \mathrm{mL}$ streptomycin). Tumor tissue was digested with collagenase type VIII $(1.5 \mathrm{mg} / \mathrm{mL}$; Sigma, USA $)$ and DNase type I ( $1 \mathrm{mg} / \mathrm{mL}$; Sigma, USA) for $120 \mathrm{~min}$ at $37{ }^{\circ} \mathrm{C}$ with gentle agitation. The resulting cell suspensions were washed in PBS, resuspended in PBS containing trypsin/EDTA, and filtered through a 40-mm nylon cell strainer (Falcon, Becton Dickinson Labware) into cold DMEM containing 10\% FBS.

\section{Isolation of $\mathrm{pDC}$ and preparation of pDC-conditioned medium (CM)}

pDC were isolated using magnetically activated cell sorting with the BDCA-4 dendritic cell isolation kit from Miltenyi Biotec according to manufacturer's instructions[21]. pDC was labeled with anti-BDCA-4 antibody coupled to colloidal paramagnetic microbeads and passed through magnetic separation columns twice (LS and RS columns; Miltenyi Biotec). The purity of the isolated pDC (APC-conjugated anti-CD $123^{+}$and PERCP-conjugated anti-MHC $\mathrm{II}^{+}$) 
was $>90 \%$. Viability was $>95 \%$ as determined using the trypan blue exclusion test. Isolated $\mathrm{pDC}$ were seeded at a final concentration of $5 \times 10^{5}$ cells $/ \mathrm{mL}$ and cultured overnight in serum-free DMEM at $37^{\circ} \mathrm{C}$ and $5 \% \mathrm{CO}_{2}$ to prepare pDC-conditioned medium ( $\mathrm{pDC}-\mathrm{CM}$ ). $\mathrm{pDC}$ were then collected by centrifugation at $3000 \mathrm{rpm}$ for further experiments, and pDC-CM were collected and stored at $-80^{\circ} \mathrm{C}$ for in vitro cancer cell line stimulation.

\section{Cell culture and stimulation}

For cell line stimulation, CAL 27 were purchased from American Type Culture Collection (ATCC ${ }^{\circledR}$ CRL-2095) and the human HNSCC cell lines, HN 30, were obtained from the National Institutes of Health (Rockville, MD, USA). HN 30 cells were seeded at a density of $4 \times 10^{5}$ and cultured in DMEM supplemented with $10 \%$ FBS in a humidified atmosphere of $5 \% \mathrm{CO}_{2}$, at $37{ }^{\circ} \mathrm{C}$ for $24 \mathrm{~h}$. The cells were washed twice with $1 \times$ PBS and starved in 1\% FBS-supplemented growth medium overnight. Next, cells were stimulated with different concentrations of pDC-CM, with or without anti-TNF-a antibodies or TNF-a (50 ng/mL; R\&D Systems, USA) for $72 \mathrm{~h}$. Experiments were repeated at a minimum of three times.

Lentiviraus-CXCR-4-shRNA was constructed at Gene Pharma (Shanghai, China). Cells were plated in 6-well plates and infected with lentivirus for $24 \mathrm{~h}$ in a complete medium containing $5 \mu \mathrm{g} / \mathrm{ml}$ polybrene.

\section{Immunohistochemical staining (IHC)}

Formalin-fixed, paraffin-embedded tissue blocks from OSCC patients were used. IHC was performed on 4-mm-thick routinely processed paraffin sections, according to a standard protocol. After deparaffinizing and rehydrating, tissue sections were incubated in sodium citrate buffer and heated for antigen retrieval. anti-CXCR-4 antibody (1:150; Rabbit; Proteintech, USA), or anti-CXCR-7 antibody (1:200; Rabbit; Proteintech, USA) was applied to tissue sections overnight at $4{ }^{\circ} \mathrm{C}$. All sections were then incubated with a corresponding secondary antibody for $30 \mathrm{~min}$ at $23-25{ }^{\circ} \mathrm{C}$. Immunohistochemical evaluations were performed independently by two pathologists who were not informed of the clinicopathological profile of the patients. CXCR-4/7 expressions were quantified using a visual grading system as previously reported [22]. According to staining intensity and percentage of positive tumor cells, the final staining score was given: 0 (negative); 1 ( $<50 \%$ weak or strong positive cells); 2 ( $>50 \%$ weak positive cells); 3 ( $>50 \%$ strong positive cells). For statistical analysis, score $(0,1)$ and $(2,3)$ were considered as low and high expression, respectively.

\section{Immunofluorescent staining}

Tissue sections were deparaffinized and rehydrated with xylene, gradient ethanol, and distilled water. After rinsing thrice with PBS, the tissue sections were blocked with 3\% BSA for $30 \mathrm{~min}$ and incubated with anti-CD123 antibody $(10 \mu \mathrm{g} / \mathrm{mL}$; goat; R\&D Systems, USA) overnight at $4{ }^{\circ} \mathrm{C}$. Tissue sections were then washed and incubated for $30 \mathrm{~min}$ with an Alexa Fluor 488-conjugated anti-mouse IgG $\mathrm{F}\left(\mathrm{ab}^{\prime}\right) 2$ fragment (1:200; Invitrogen, USA). Cells were co-stained with 4',6-diamidino-2-phenylindole (1:300; Invitrogen) to detect nuclei, after which they were observed and imaged using a TCS SP2 laser-scanning confocal microscope (Leica Microsystems, Germany). Based on CD123 staining, pDC infiltrates were considered low if $<10$ pDC per high-power field (HPF, 400×) were observed, high if $>10 \mathrm{pDC}$ per $\mathrm{HPF}$ were observed [23].

\section{Flow cytometry}

Flow cytometric analysis was performed as previously described by Hartmann et al. [21]. Briefly, cells were incubated at $4{ }^{\circ} \mathrm{C}$ for $30 \mathrm{~min}$ in PBS with $0.1 \% \mathrm{BSA}$ and $0.01 \% \mathrm{NaN}_{3}$ in the presence of appropriately diluted labeled monoclonal antibodies, which were purchased from BD Pharmingen (USA) and used as follows: APC-conjugated anti-CD123+ and PERCP-conjugated anti-MHC $\mathrm{II}^{+}$. The cells were subsequently analyzed using a FACSCalibur and CellQuest FACS analysis software (BD Biosciences, Erembodegem-Aalst, Belgium).

\section{Cytokine production analysis}

The Bio-Plex Cytokine Assay (Bio-Rad, Munich, Germany) was used for detection of IL-6, IL-8, and TNF-a. An IFN-a module set from Bender Med Systems (Vienna, Austria) was used to detect IFN-a in cell culture supernatants, according to the manufacturer's instructions. These cytokine assays allowed for the multiplexed quantitative measurement of multiple cytokines in a small volume of cell culture supernatant. The protein array was analyzed by a dedicated microplate reader system (Bio-Plex Array Reader; Bio-Rad) and data were calculated by the Bio-Plex Manager software. Experiments were repeated at a minimum of three times.

\section{Quantitative real-time PCR (qPCR)}

The preparation of total RNA and cDNA was performed as previously described [24]. CXCR-4 (primer sequences: upstream, 5'-ACTACACCGAGG AAATGGGCT-3'; downstream, 5'-GCTACCCACA ATGCCAGTTAAGAAGA-3'), CXCR-7 (primer sequences: upstream, 5'-TCTGCATCTCTTCGACTAC 
TCA-3'; downstream, 5'-GTAGAGCAGGACGCTTTT GTT-3'), and glyceraldehyde 3-phosphate dehydrogenase (GAPDH; primer sequences: upstream, 5'- GGAGCGAGATCCCTCCAAAAT-3', downstream; 5'- GGCTGTTGTCATACTTCTCA TGG-3') mRNA were detected by real-time PCR using the TaqMan ${ }^{\mathrm{TM}}$ Gene Expression Assay (Applied Biosystems, Life Technologies Life Technologies, USA). Gene-specific products were measured continuously by an ABI PRISM 7000 Sequence Detection System (Applied Biosystems) over 40 cycles. Experiments were repeated at a minimum of three times.

\section{Western blotting (WB)}

Cells were treated with lysis buffer (PBS containing $1 \%$ Triton $\mathrm{X}-100$, protease inhibitor cocktail, and $1 \mathrm{mmol} / \mathrm{L}$ phenylmethylsulfonyl fluoride) at $4{ }^{\circ} \mathrm{C}$ for $30 \mathrm{~min}$. Equal concentrations of protein were subjected to SDS-PAGE. Following transfer to a Immobilon-P Transfer Membrane, successive incubations with anti-CXCR-4 (1:500; Rabbit; Proteintech, USA), CXCR-7 (1:500; Rabbit; Proteintech, USA), p65 (0.5 $\mu \mathrm{g} / \mathrm{mL}$; Abcam, USA), p-p65 (0.5 $\mu \mathrm{g} / \mathrm{mL}$; Abcam, USA), and p-Iкb (0.6 $\mu \mathrm{g} / \mathrm{mL}$; Santa Cruz Biotechnology, Inc., Santa Cruz, CA, USA) antibodies or anti-GAPDH antibody (Sangon Biotech) were performed, followed by corresponding horseradish peroxidase-conjugated secondary antibody (Sangon Biotech) incubation. The immunoreactive proteins were then detected using the ECL system (NCM Biotech, Suzhou, China). Bands were scanned using a densitometer (GS-700; Bio-Rad) and quantification was performed via Quantity One 4.6.3 software (Bio-Rad). Experiments were repeated at a minimum of three times.

\section{Cell proliferation assay}

Cell proliferation assays were performed using Cell Counting Kit-8 (CCK-8; Dojindo, USA). Cells were plated in 96-well plates at $3 \times 10^{4}$ cells per well and incubated for five days. Each day, $10 \mathrm{uL}$ CCK-8 solution was added to each well. The OD value was read at $450 \mathrm{~nm}, 2 \mathrm{~h}$ after CCK-8 addition, according to the manufacturer instructions, and the cell viability was measured at intervals of $24 \mathrm{~h}$. Experiments were repeated at a minimum of three times.

\section{Colony formation assay}

Oral cancer cells (CAL 27, HN 30) were seeded at 1,000 cells per well in a 6-well plate and incubated overnight at $37{ }^{\circ} \mathrm{C}$. The cells were treated with different concentrations of pDC-CM containing 10\% FBS. Control wells were treated with DMEM containing 10\% FBS alone. The plates were incubated for 14 days; during this period, the medium was changed twice per week with the appropriate concentration of $\mathrm{pDC}-\mathrm{CM}$. The plates were washed with ice-cold PBS, colonies were fixed with methanol for $15 \mathrm{~min}$, stained with $2 \%$ crystal violet, and counted. Colonies consisting of $\geq 50$ counts were scored. Experiments were repeated at a minimum of three times.

\section{Scratch wound healing assay}

Cells were treated with different concentration of pDC-CM after creating a wound across the cell monolayer with a plastic tip. Cell migration into the wound surface was then measured every $6 \mathrm{~h}$. Experiments were repeated at a minimum of three times.

\section{Cell migration and invasion assay}

The cell migration assay was performed with transwell chambers $(0.8 \mu \mathrm{m}$ pores; Merck Millipore, USA), while the cell invasion assay was implemented by coating the upper surface of the transwell chambers with Matrigel (BD Biosciences, USA). Cells $\left(3 \times 10^{4}\right)$ were resuspended in serum-free DMEM and different concentrations of $\mathrm{pDC}-\mathrm{CM}$ were added to the interior of the inserts. DMEM containing 20\% FBS was added to the lower chamber as a chemoattractant. Cells were incubated for $48 \mathrm{~h}$ at $37{ }^{\circ} \mathrm{C}$ in a $\mathrm{CO}_{2}$ incubator $\left(5 \% \mathrm{CO}_{2}\right)$. Cells that migrated or invaded through the membrane were fixed and stained with crystal violet. Images of five randomly selected fields containing fixed cells were captured, and cells were counted. Experiments were repeated at a minimum of three times.

\section{Statistical analysis}

Data are presented as mean \pm standard deviation (SD) of at least three independent experiments. Comparisons of independent samples were performed using Student's $t$-test or nonparametric tests when appropriate (SPSS 11.0, Chicago). Correlation analyses were done using the Chi-square test or Spearman's rank correlation coefficient. Statistical significance was defined as $P<0.05$ for all analyses.

Table 1. Correlations between tumor-infiltrating $\mathrm{PDC}$ and clinicopathologic parameters of OSCC patients $(N=122)$

\begin{tabular}{|c|c|c|c|}
\hline \multirow{2}{*}{$\begin{array}{l}\text { Clinicopathologic } \\
\text { parameters }\end{array}$} & \multicolumn{2}{|c|}{ Tumor-infiltrating pDC } & \multirow{2}{*}{$P$-value } \\
\hline & Low $(\%)(\mathrm{N}=78)$ & High $(\%)(N=44)$ & \\
\hline Age (year) & & & 0.563 \\
\hline$<50$ & $33(27.0 \%)$ & $21(17.2 \%)$ & \\
\hline$\geq 50$ & $45(36.9 \%)$ & $23(18.9 \%)$ & \\
\hline Gender & & & 0.187 \\
\hline Male & $40(32.8 \%)$ & $28(23.0 \%)$ & \\
\hline Female & $38(31.1 \%)$ & $16(13.1 \%)$ & \\
\hline Alcohol use & & & 0.729 \\
\hline Yes & $38(31.1 \%)$ & $20(16.4 \%)$ & \\
\hline
\end{tabular}




\begin{tabular}{|c|c|c|c|}
\hline \multirow{2}{*}{$\begin{array}{l}\text { Clinicopathologic } \\
\text { parameters }\end{array}$} & \multicolumn{2}{|c|}{ Tumor-infiltrating pDC } & \multirow[t]{2}{*}{$P$-value } \\
\hline & Low (\%) $(\mathrm{N}=78)$ & $\operatorname{High}(\%)(\mathrm{N}=44)$ & \\
\hline No & $40(32.8 \%)$ & $24(19.7 \%)$ & \\
\hline Smoking & & & 0.289 \\
\hline Yes & $33(27.0 \%)$ & $23(18.9 \%)$ & \\
\hline No & $45(36.9 \%)$ & $21(17.2 \%)$ & \\
\hline Tumor size & & & $0.045^{*}$ \\
\hline $\mathrm{T} 1 / \mathrm{T} 2$ & $50(41.0 \%)$ & $20(16.4 \%)$ & \\
\hline $\mathrm{T} 3 / \mathrm{T} 4$ & $28(23.0 \%)$ & $24(19.7 \%)$ & \\
\hline Lymph node metastasis & & & $0.022^{*}$ \\
\hline Yes & $31(25.4 \%)$ & $27(22.1 \%)$ & \\
\hline No & 47 (38.5\%) & $17(13.9 \%)$ & \\
\hline Distant metastasis & & & 0.965 \\
\hline Yes & $18(14.8 \%)$ & $10(8.2 \%)$ & \\
\hline No & $60(49.2 \%)$ & $34(27.9 \%)$ & \\
\hline Tumor differentiation & & & 0.187 \\
\hline Well & $40(32.8 \%)$ & $28(23.0 \%)$ & \\
\hline Moderate/poorly & $38(31.1 \%)$ & $16(13.1 \%)$ & \\
\hline
\end{tabular}

\section{Results}

\section{Increased pDC infiltration correlates with}

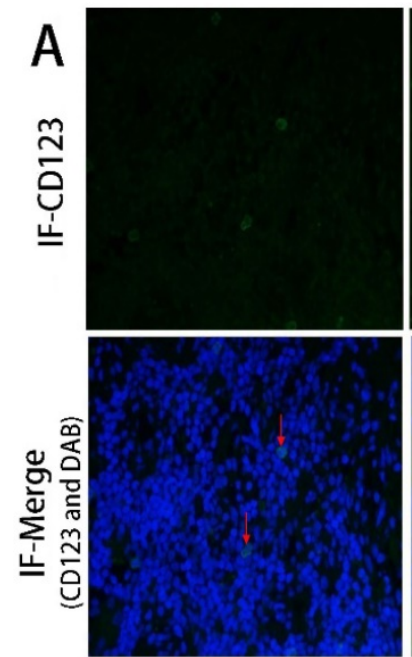

Low pDC infiltration $\operatorname{OSCC}^{\operatorname{LN}(-)}$

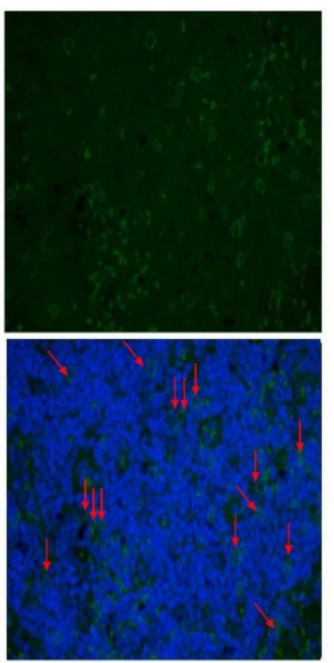

High pDC infiltration $\operatorname{OSCC}^{\mathrm{LN}(+)}$

\section{tumor growth and lymph node metastasis in OSCC patients}

We first evaluated the level of pDC infiltration in the paraffin-embedded tumor tissue sections of 122 OSCC patients using immunofluorescence. Results showed tumor-infiltrating $\mathrm{pDC}$ was positively correlated with tumor size $(P=0.045)$, and lymph node metastasis $(P=0.022)$ (Table 1$)$. Significant increased tumor-infiltrating $\mathrm{pDC}$ was seen in carcinoma tissues of OSCC patients with lymph node metastasis (OSCC ${ }^{\operatorname{LN}(+)}$ ) compared to that of without lymph node metastasis (OSCC $\left.{ }^{\mathrm{LN}(-)}\right)$ (Figure 1A). More important, survival analysis of 122 OSCC patients demonstrated that increased tumor-infiltrating $\mathrm{pDC}$ was a strong predictor of poor outcome $(P=0.0095$; Figure 1B). Further flow cytometry analysis from 60 freshly resected OSCC tissues and 6 normal oral mucosa also demonstrated a significantly higher $\mathrm{pDC}$
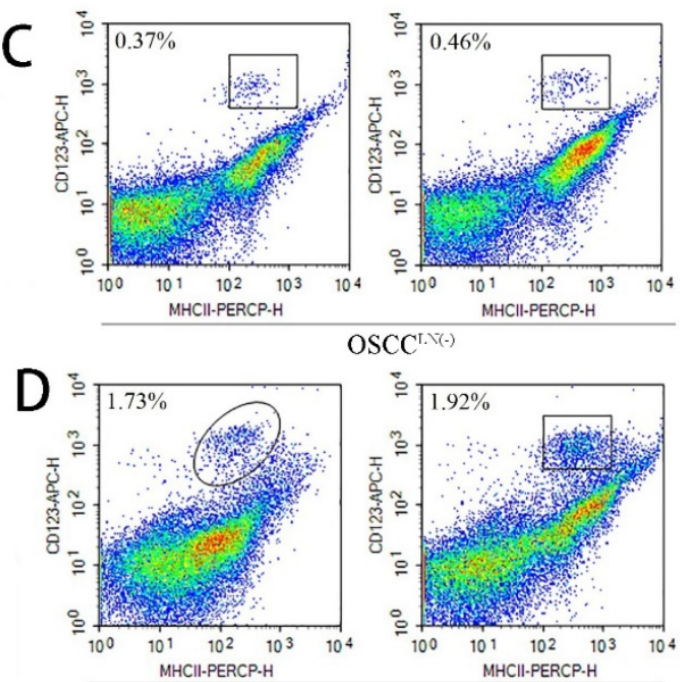

$\mathrm{OSCC}^{\mathrm{LN}(-)}$
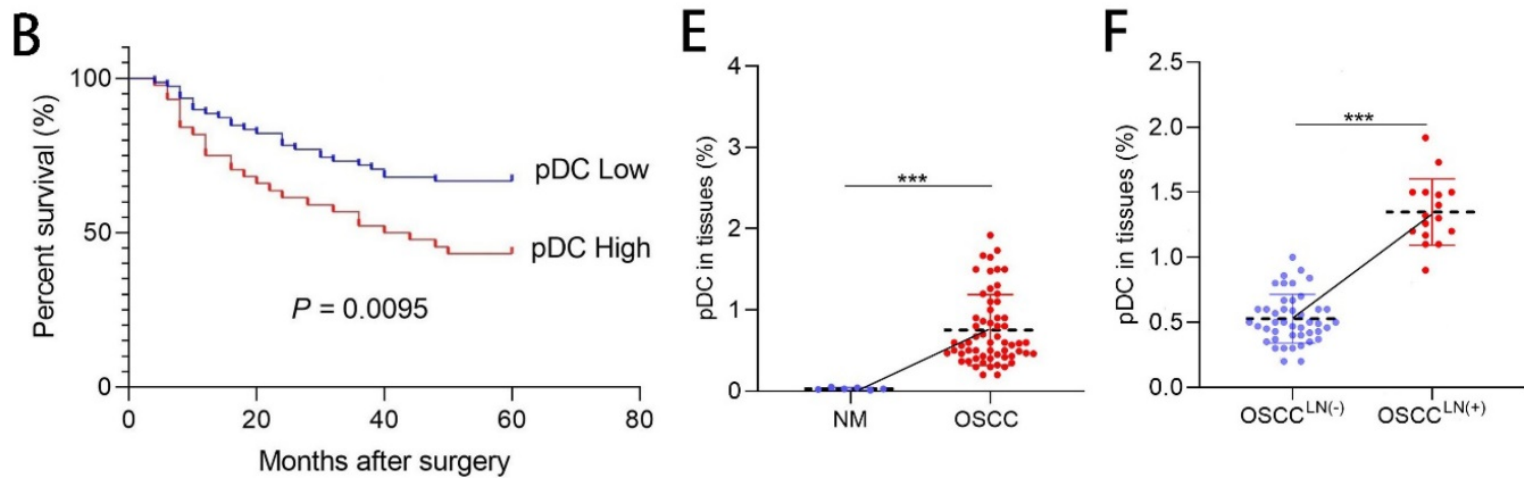

Figure 1. Tumor-infiltrating $\mathrm{PDC}$ in OSCC tissue. (A) Representative image of tumor-infiltrating $\mathrm{pDC}$ in OSCC tissue as visualized by immunofluorescence. (Low: $<10 \mathrm{pDC}$ per HPF; high: > 10 pDC per HPF), Magnification: 400x. The red arrow indicates the stained cell of interest. (B) Cumulative survival rate of OSCC patients with low level and high level PDC infiltration. (C) Representative image of low infiltrated PDC in tumor tissue of OSCCLN(-) patients by flow cytometry. (D) Representative image of high tumor-infiltrating PDC in tumor tissue of OSCCLN(+) patients by flow cytometry. (E) Flow cytometry results showed tissue-infiltrating PDC were significantly higher in the OSCC tissue compared with normal oral mucosa. (F) Flow cytometry results showed tissue-infiltrating PDC were significantly higher in OSCCLN(+) tissue compared with OSCCLN(-) tissue. NM, Normal oral mucosa epithelium. OSCCLN(-), OSCC patients without lymph node metastasis. OSCCLN(+), OSCC patients with lymph node metastasis. $* P<0.05$, $* * * P$ $<0.001$. 
population $(1.35 \pm 0.25 \%)$ in carcinoma tissues of OSCC ${ }^{\mathrm{LN}(+)}$ patients compared to OSCC ${ }^{\mathrm{LN}(-)}$ patients. $(0.53 \pm 0.19 \%)(P<0.01$; Figure 1C-F $)$.

\section{pDC-CM promote oral cancer cell proliferation and invasion in vitro}

Next, the impact of tumor-infiltrating pDC on oral cancer cell was investigated. pDC were isolated and cultured overnight to prepare $\mathrm{pDC}$-conditioned medium (pDC-CM). The CCK-8 and colony formation assay revealed that $\mathrm{pDC}-\mathrm{CM}$ significantly enhanced the rate of cell proliferation and colony formation in Cal 27 and HN 30 cell lines $(P<0.05$; Figure 2A, 2C).

A
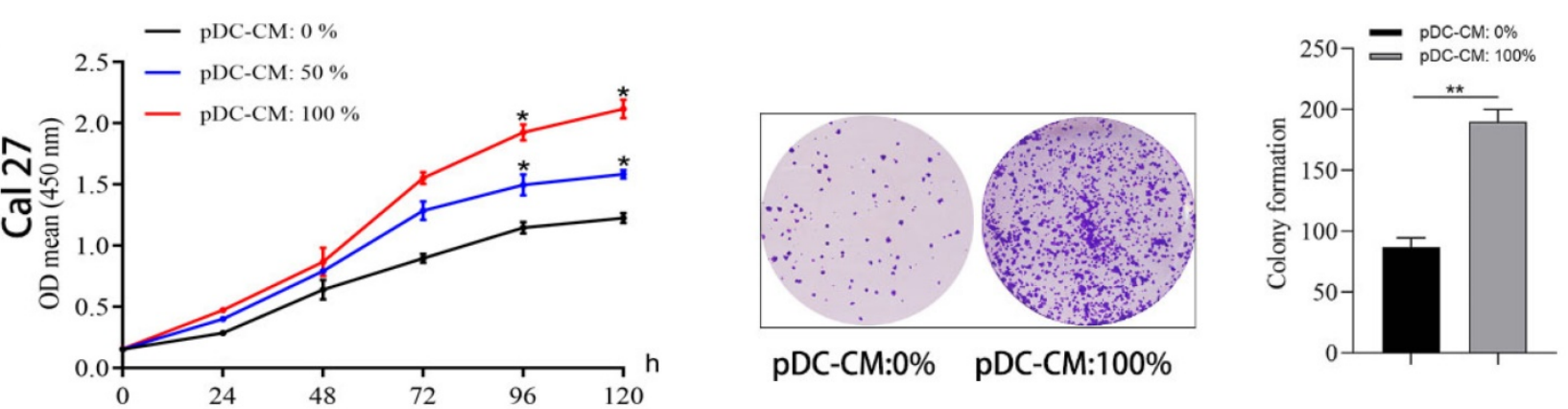

B
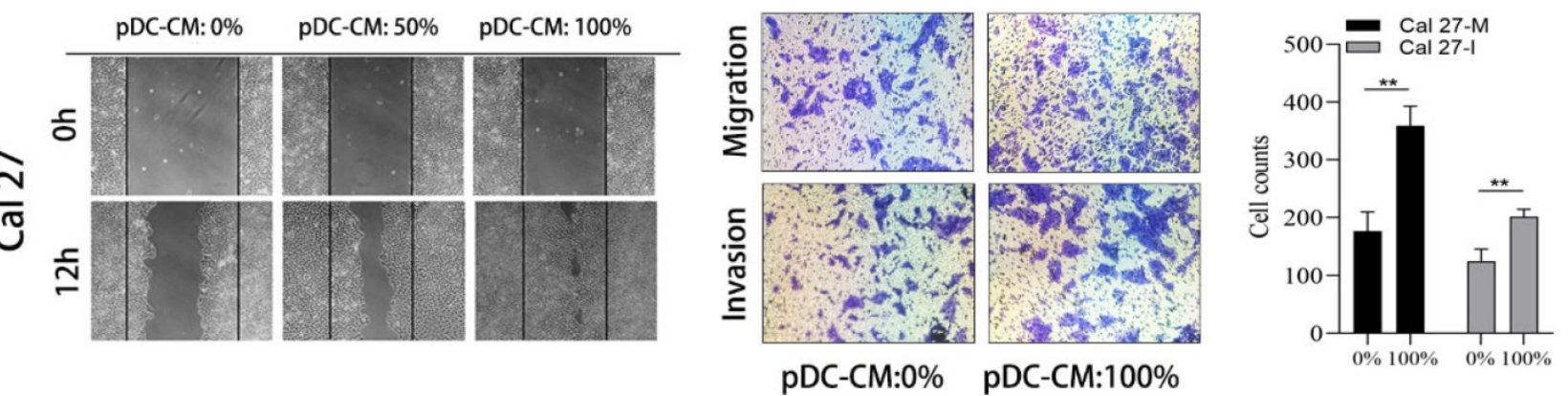

C
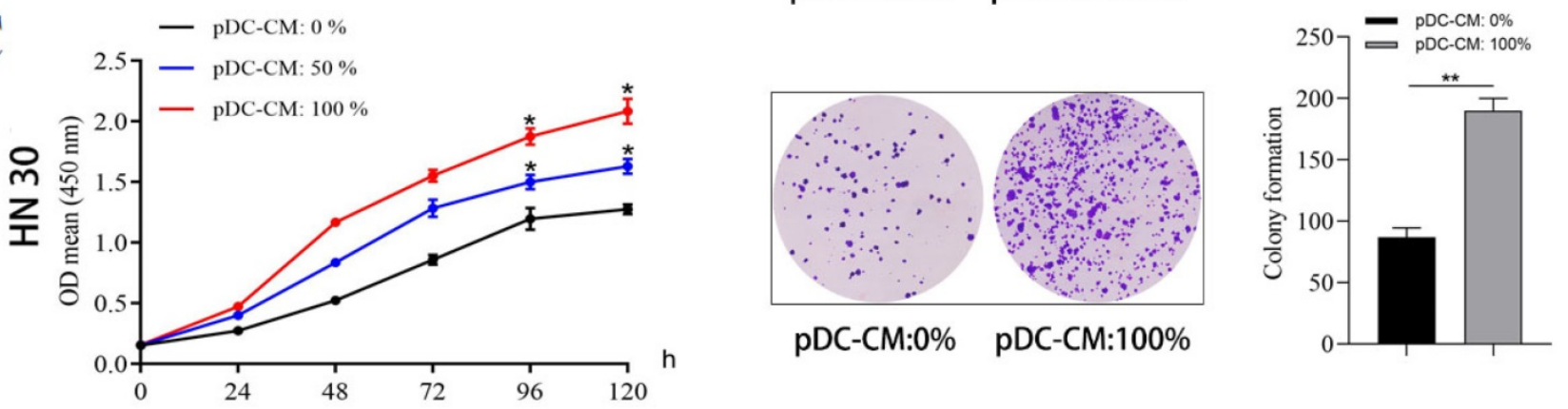

D
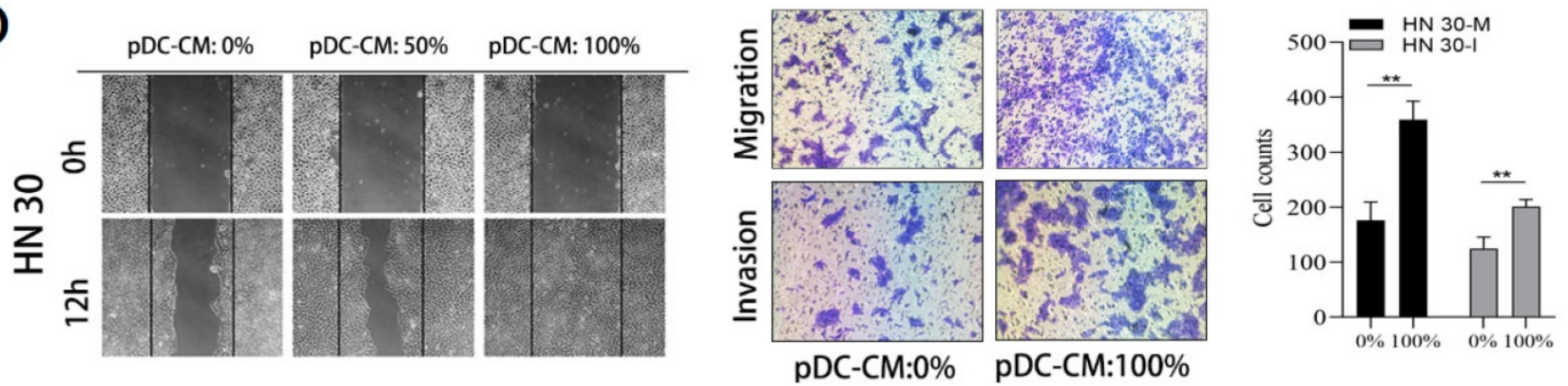

Figure 2. Tumor-infiltrating pDC promote oral cancer cell proliferation, migration and invasion in vitro. pDC were isolated and seeded at a final concentration of $5 \times 10^{5}$ cells $/ \mathrm{mL}$ and cultured overnight in serum-free DMEM at $37{ }^{\circ} \mathrm{C}$ and $5 \% \mathrm{CO}_{2}$ to prepare pDC-conditioned medium (pDC-CM). Oral cancer cells were stimulated with different concentrations of PDC-CM. (A) pDC-CM promote Cal 27 cell proliferation in a concentration-dependent manner as reflected by CCK-8 and colony formation assays. (B) pDC-CM promote Cal 27 cell migration and invasion as reflected by the scratch and transwell assays. (C) pDC-CM promote HN 30 cell proliferation in a concentration-dependent manner as reflected by CCK-8 and colony formation assays. (D) pDC-CM promote HN 30 cell migration and invasion as reflected by the scratch and transwell assays. The images from scratch assays were photographed every $6 \mathrm{~h}$. Transwell assay magnification, $200 \times$. Experiments were repeated at a minimum of three times. PDC-CM: $0 \%$, DMEM containing 10\% FBS; PDC-CM: $50 \%$, Add an equal volume of DMEM containing $10 \%$ FBS to the original pDC-CM; pDC-CM: $100 \%$, undiluted pDC-conditioned media. Cal $27(\mathrm{HN} 30)-\mathrm{M} / \mathrm{l}$, cells that migrated $(\mathrm{M})$ or invaded (I) through the transwell chamber. $*, P<0.05$. $* *, P<0.01$. 
Moreover, wound healing and transwell assays revealed that the migration and invasion capability of oral cancer cells treated with different concentrations of pDC-CM increased remarkably in comparison with that of untreated oral cancer cells $(P<0.01$; Figure 2B, $2 D)$, suggesting that tumor-infiltrating $\mathrm{pDC}$ have the ability to promote cancer cell proliferation, migration and invasion in vitro.

\section{Increased pDC infiltration positively correlates with CXCR-4 expression in OSCC}

CXCR-4 and CXCR-7 mRNA expression of 60 freshly resected OSCC tissues and 6 normal oral mucosa were detected by qPCR. Results show that both CXCR-4 and CXCR-7 mRNA expression in the carcinoma tissue of $\mathrm{OSCC}^{\mathrm{LN}(+)}$ patients were significantly higher than that in OSCC ${ }^{\mathrm{LN}(-)}$ patients (Figure 3A-D). IHC detection also showed an increased CXCR-4 and CXCR-7 protein expression in carcinoma tissues of $\mathrm{OSCC}^{\mathrm{LN}(+)}$ patients compared to that of OSCCLN(-) patients (Figure 3E). In addition, we performed Spearman's rank correlation coefficient analysis and found a significant positive relationship between tumor-infiltrating $\mathrm{pDC}$ and CXCR-4 expression $(r=0.669, P<0.01$, Supplemental Table 1). However, such significance was not observed between tumor-infiltrating $\mathrm{pDC}$ and CXCR-7 ( $\mathrm{r}=$ 0.024, $P=0.84$, Supplemental Table 1), suggesting that CXCR-4 may play a more important role in pDC-mediated lymph node metastasis.
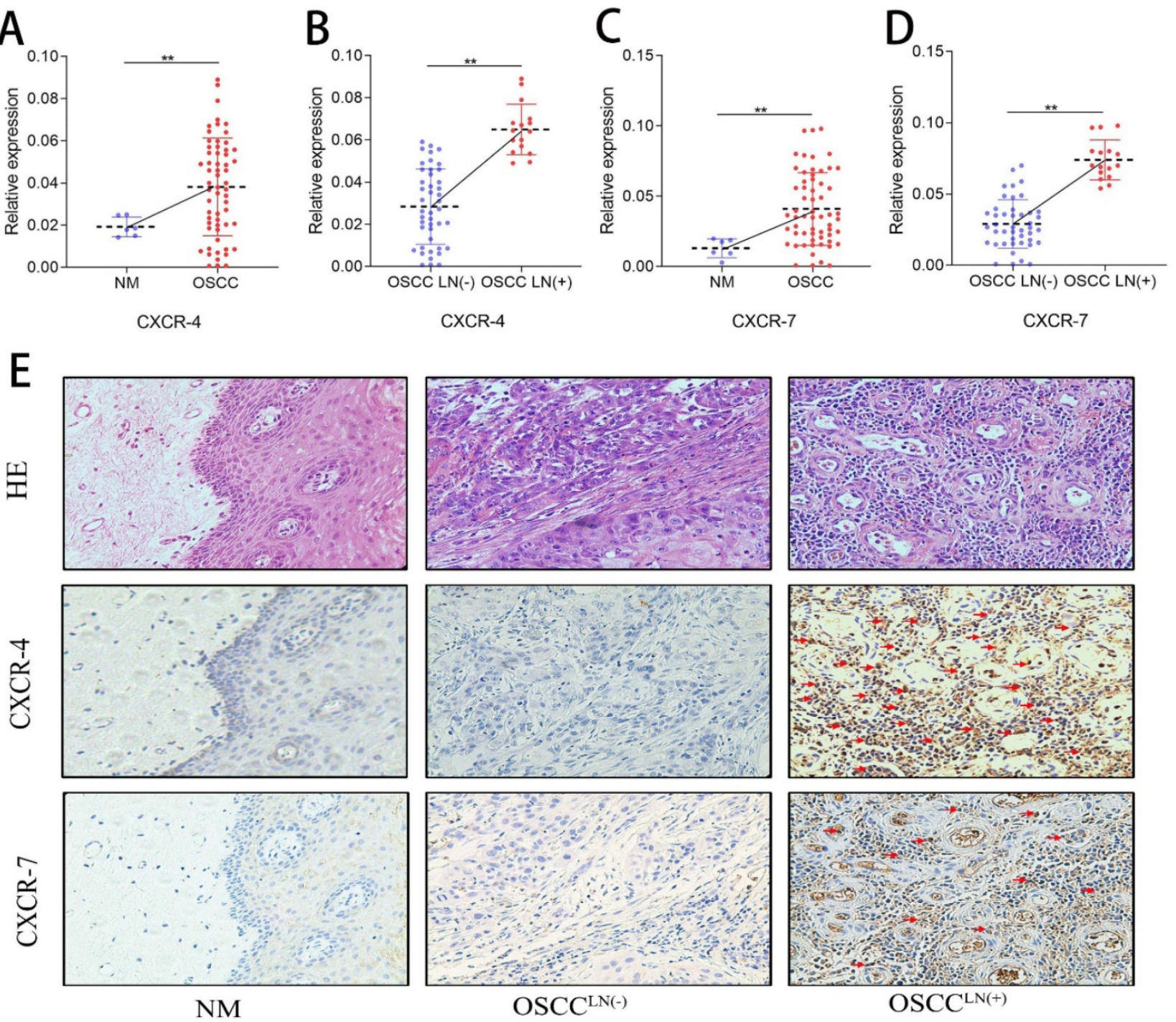

$\operatorname{OSCC}^{\mathrm{LN}(-)}$

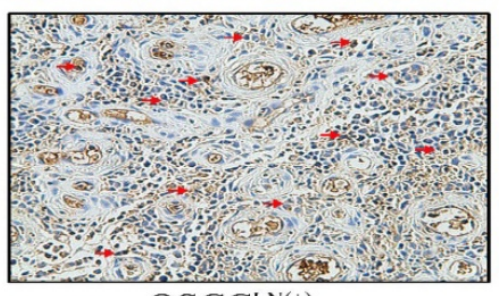

$\operatorname{OSCC}^{\mathrm{LN}(+)}$

Figure 3. CXCR-4/7 expression in OSCC patients. (A) CXCR-4 mRNA expression was significantly higher in OSCC tissue compared with normal oral mucosa. (B) CXCR-4 mRNA expression was significantly greater in OSCCLN(+) tissues compared with OSCCLN(-) tissues. (C) CXCR-7 mRNA expression was significantly higher in the OSCC tissue compared with normal oral mucosa. (D) CXCR-7 mRNA expression was significantly greater in OSCCLN(+) tumor tissues compared with OSCCLN(-) tissues. (E) Representative image of HE and IHC staining for CXCR-4 and CXCR-7 in normal oral mucosa, OSCCLN(-) and OSCCLN(+) tumor tissue. Experiments were repeated at a minimum of three times. The red arrow indicates the stained cell of interest. NM, Normal oral mucosa epithelium; OSCCLN(-), OSCC patients without lymph node metastasis; OSCCLN(+), OSCC patients with lymph node metastasis. ${ }^{* *}, P<0.01$. 

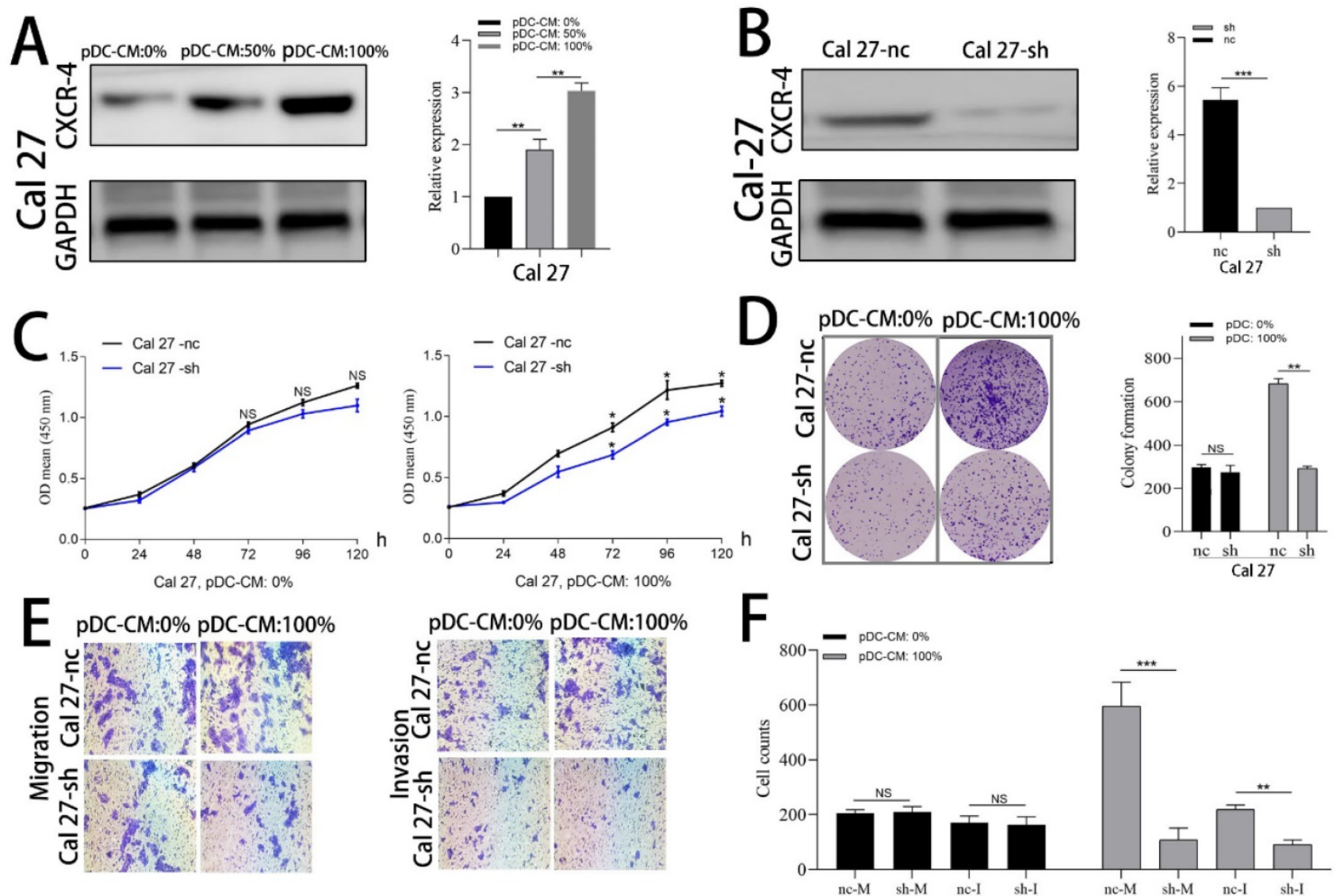

Figure 4. CXCR-4 is involved in PDC-mediated Cal 27 cells proliferation, migration and invasion. (A) Increased CXCR-4 expression was detected by western blotting after PDC-CM treatment in Cal 27 cells for 72 hours. (B) Cal 27 cells were cultured in 6-well cell culture plates and transfected with the lentiviraus-CXCR-4-shRNA(sh) or negative control (nc). CXCR-4 expression was further detected by western blotting after transfection. The effect of pDC-CM on Cal 27-nc and Cal 27-sh growth rates were assessed by CCK-8 (C) and colony formation assays (D). (E) Representative image of cell migration and invasion by transwell assay. (F) Cal 27 cell migration (nc/sh-M) and invasion (nc/sh-l) were both decreased in the CXCR-4-silenced group upon PDC-CM treatment. NS, no significance. *, $P<0.05 ; * *, P<0.01 ; * * *, P<0.001$.

\section{CXCR-4 is involved in PDC-mediated oral cancer cell proliferation and invasion}

Cal 27 and HN 30 cell lines were treated with pDC-CM for $72 \mathrm{~h}$. Western blotting analysis showed that CXCR-4 expression of both Cal 27 and HN 30 were significantly increased in a concentrationdependent manner following $\mathrm{pDC}-\mathrm{CM}$ treatment (Figure 4A; Supplemental Fig. 1A). We then used lentiviraus-CXCR-4-shRNA to silence CXCR-4 expression in Cal 27 (Figure 4B) and HN 30 (Supplemental Fig. 1B) cell lines and found that pDC-CM-mediated tumor cell proliferation was significantly inhibited in CXCR-4-silenced cells, as reflected by the CCK-8 (Figure 4C; Supplemental Fig. 1C) and colony formation (Figure 4D; Supplemental Fig. 1D) assays. In addition, Cells that migrated or invaded through the transwell chamber were also decreased in the CXCR-4-silenced cells upon pDC-CM treatment $(P<0.01$; Figure 4E, F; Supplemental Fig. 1E, F), suggesting that CXCR-4 may play an important role in pDC-mediated cancer cell proliferation, migration and invasion.

\section{NF-kB activation contributes to pDC- mediated CXCR-4 overexpression in oral cancer cells}

We further examined the activity of NF-kB pathway via western blotting. Results showed that NF-KB p65 was significantly decreased in the cytoplasm of Cal 27 cells treated with pDC-CM, while phosphorylated-p65 and phosphorylated IкB significantly increased following pDC-CM treatment (Figure 5A, B). Moreover, NF-kB inhibitor PDTC was then used in Cal 27 cells treated with pDC-CM, and resulted in no significantly change of CXCR-4 expression, NF-kB activation (Figure 5C,D), cancer cell proliferation (Figure 5E,F) and invasion (Figure 6A,B), suggesting that pDC-CM-mediated CXCR-4 overexpression in oral cancer Cal 27 cells occurs, in part, through the NF-kB pathway.

\section{pDC-mediated NF-KB activated CXCR-4 overexpression is partly induced by pDC-derived TNF- $\alpha$ secretion}

To further decipher the mechanism by which pDC-CM induces NF-kB pathway activation, we 
chose four stimulating factors, including TNF-a, IL-6, IL-8, and IFN-a. ELISA results showed that the concentration of TNF- $\alpha$ in $\mathrm{LN}^{+}$pDC-CM was higher than that in $\mathrm{LN}^{-}$pDC-CM, suggesting that TNF-a secreted by tumor-infiltrating $\mathrm{pDC}$ may contribute to NF-kB activation in oral cancer cells (Figure 6C). We then used an anti-TNF- $\alpha$ antibody to neutralize pDC-CM-derived TNF- $\alpha$, which caused significant inhibition of the pDC-CM-mediated NF-kB activity and CXCR-4 expression in Cal 27 cells (Figure 6D). Conversely, purified TNF-a treatment resulted in enhanced NF-kB activity and CXCR-4 expression (Figure 6D), which further suggests that TNF-a is an important mediator of tumor-infiltrating $\mathrm{pDC}$ in the promotion of tumor growth and metastasis.

\section{Discussion}

Crosstalk between tumor cells and tumorinfiltrating immune cells is extremely important for cancer development and treatment outcome [25]. Cancer cells can secrete immunomodulatory cytokines that act on immune cells, impairing their function and facilitating tumorigenesis [26]. Accordingly, these infiltrated immune cells can also promote tumor progression and metastasis through communication with cancer cells via secreted growth factors that directly affect cell motility, and chemokines that induce cancer cell migration to specific organs [27]. Previously, our study provided strong evidence that oral cancer cells can secrete immunosuppressive mediators, such as TGF- $\beta$ and IL-10, which in turn lead to the impaired function of tumor-infiltrating $\mathrm{pDC}$ [20]. The present study shows that these impaired $\mathrm{pDC}$ in the pre-tumor microenvironment can also promote cancer cell proliferation and migration via NF-kB-activated CXCR-4 overexpression by a paracrine mechanism.
A
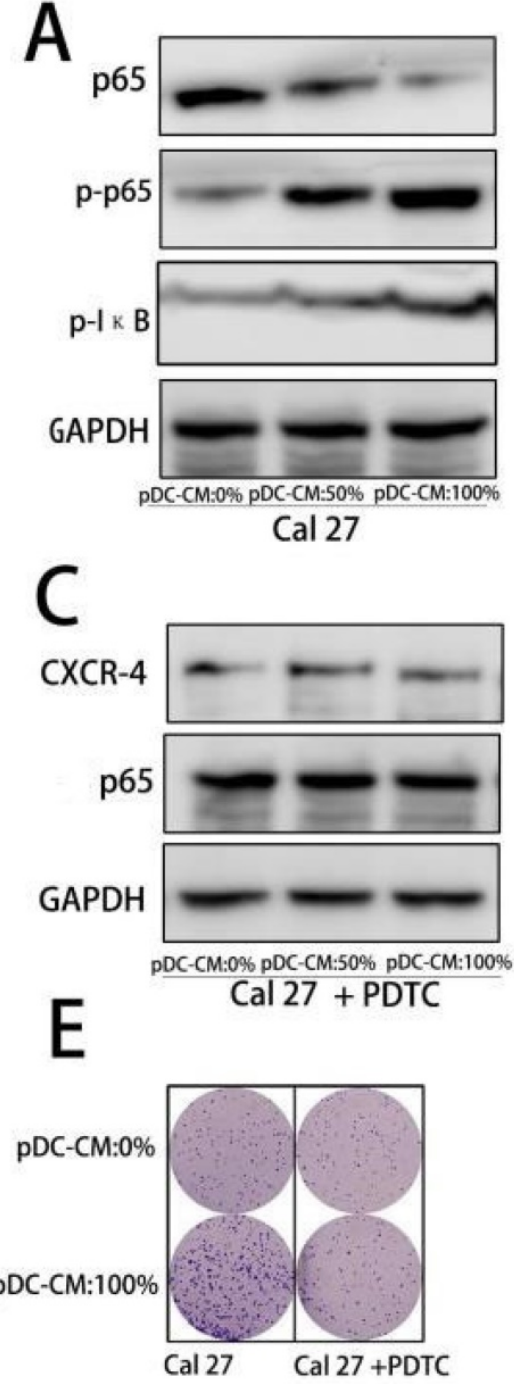
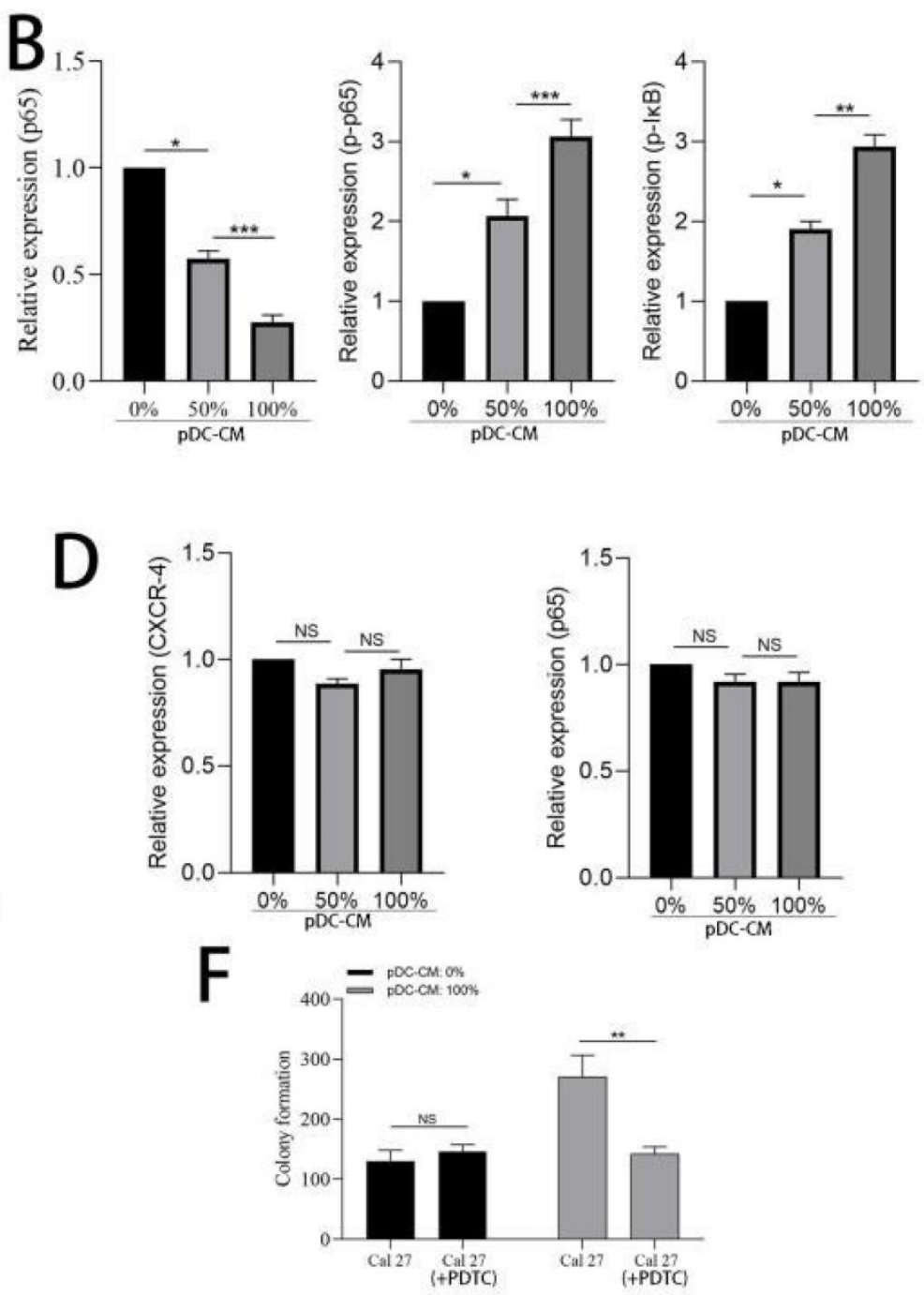

Figure 5. Activation of NF-KB in pDC-mediated CXCR-4 overexpression in oral cancer cells. A/B. Increased NF-KB activity in pDC-CM-treated Cal 27 cells assessed by western blotting. C/D. NF- $\kappa B$ inhibitor PDTC down-regulated pDC-CM-mediated CXCR-4 overexpression in Cal 27 cells. E/F. PDTC decreased pDC-CM-mediated oral cancer cell proliferation as reflected by colony formation assay. Experiments were repeated at least three times. $*, P<0.05$. $* *, P<0.01 . * * *, P<0.001$. 


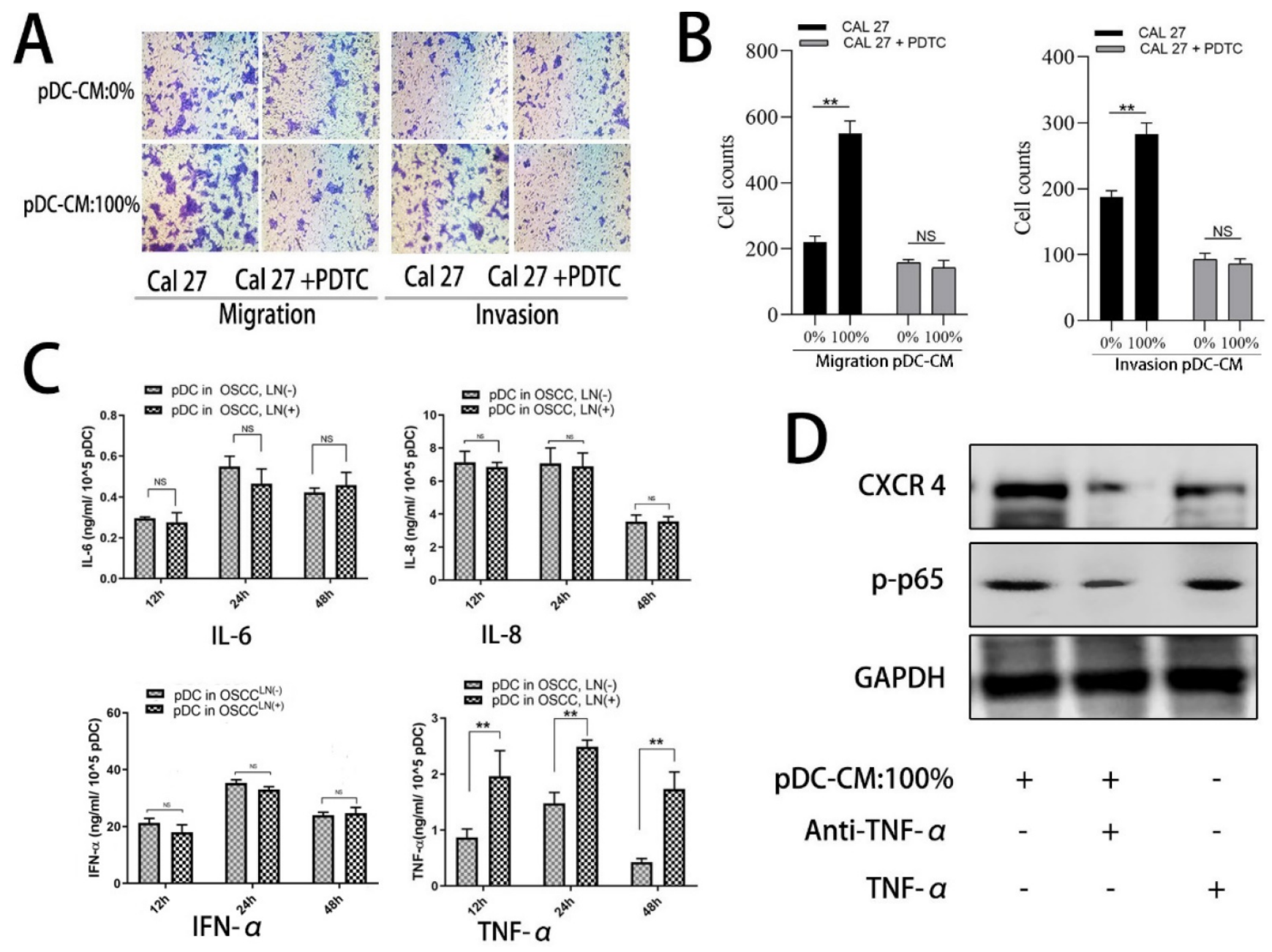

Figure 6. TNF- $\alpha$ is involved in pDC-mediated NF-KB activity in OSCC Cal 27 cells. A/B. NF-KB inhibitor, PDTC, decreased pDC-CM-mediated oral cancer Cal 27 cell migration and invasion as reflected by transwell assay. C. TNF- $\alpha$ secretion was higher in PDC-CM from OSCCLN(+) patients than that in pDC-CM from OSCCLN(-) patients. D. TNF- $\alpha$ neutralizing antibody partly reversed pDC-CM-mediated NF-KB activity and CXCR-4 overexpression in Cal27 cells as shown by western blotting analysis. The data are representative of at a minimum of three experiments. NS, No significance. $* * P<0.01$.

Metastasis to regional LNs is an important step in cancer progression and is commonly used to predict poor clinical outcome [28]. Accumulating evidence suggests that tumor-infiltrating immune cells are closely related to LN metastasis. For example, increased $\mathrm{CD}^{+} \mathrm{T}$ cell and M1 TAM infiltration are often correlated with a low incidence of LN metastasis, while increased regulatory T cells and M2 TAMs primarily indicate a high incidence of LN metastasis [5]. However, the relationship between tumor-infiltrating $\mathrm{pDC}$ and LN metastasis is rarely reported. In 2017, we first reported that tumor-infiltrating $\mathrm{pDC}$ are closely related to $\mathrm{LN}$ metastasis in OSCC patients [19]. Similarly, this year, Gadalla et al. also found a significant increase in tumor-infiltrating $\mathrm{pDC}$ in breast cancer tissues of $\mathrm{LN}^{+}$ patients compared to that of $\mathrm{LN}^{-}$patients [29]. Unfortunately, none of these studies clarified whether tumor-infiltrating $\mathrm{pDC}$ are effective as a predictor for LN metastasis based on a large clinic sample. In the present study, we collected clinicopathological data and follow-up information from 122 OSCC patients to confirm the predicted role of tumor-infiltrating $\mathrm{pDC}$ in oral cancer LN metastasis.

In the present study, we interestingly found that tumor-infiltrating $\mathrm{pDC}$ were highly present in OSCC tissues expressing high levels of CXCR-4. We speculated that there may be an interaction between pDC infiltration and CXCR-4 expression in the oral cancer microenvironment. CXCR-4, one of the chemokine receptors belonging to the CXC receptor family, plays a significant role in cancer cell proliferation and migration [30]. High levels of CXCR-4 were found in breast cancer cells, which is believed to indicate the metastatic destination of tumor cells [31]. Loss of cell surface CXCR-4 expression on hematopoietic stem cells is associated with decreased migration activity [32]. In oral cancer, CXCR-4 has been found to be upregulated in LN metastatic OSCC cell lines compared with nonmetastatic cell lines [33]. Moreover, CXCR-4 stably transfected in oral cancer cells frequently induces 
metastasis to cervical LN in nude mice [34]. In parallel with these results, we confirmed an increased expression of CXCR-4 in primary oral cancer patient tumors with LN metastases. Importantly, we also demonstrated that pDC-CM could significantly promote OSCC proliferation and migration via increasing CXCR4 expression in vitro, as reflected by the colony formation and transwell assays, suggesting that tumor-infiltrating $\mathrm{pDC}$ may contribute to the overexpression of CXCR-4, and subsequent growth and metastasis in oral cancer.

The signal transduction pathways that modulate the activity of CXCR-4 transcription factors are highly diverse. A number of which, including the nuclear respiratory factor-1, SP-1, NF-kB, and activator protein-1 pathways, have been reported to be responsible for constitutive and inducible expression of CXCR-4 [35]. The present study provides sufficient evidence to suggest direct involvement of NF-KB in the regulation of CXCR-4 expression in OSCC. Similarly, a study showed that constitutively active NF-kB upregulates CXCR-4 expression and promotes tumor cell migration and metastasis in breast cancer cells [36]. Another study in cervical cancer also found that NF- $\mathrm{kB}$ promotes cancer cell migration to the lung via upregulation of CXCR-4 expression [37]. Therefore, our results, as well as those published by others, support the therapeutic benefits of NF-KB inhibitors for metastatic cancer patients.

Several reports have described the secretion of various factors by tumor-infiltrating immune cells, including TNF- $\alpha$, IL-10, and TGF- $\beta$, as impacting the NF-kB pathway [38]. However, it has yet to be clearly established which factors have an important role in pDC-CM-mediated NF- $\mathrm{kB}$ activation in oral cancer. Interestingly, our ELISA results indicate a higher secretion of TNF- $\alpha$ in $\mathrm{pDC}$ isolated from $\mathrm{LN}^{+}$cancer tissue in comparison with that of $\mathrm{pDC}$ from $\mathrm{LN}^{-}$ cancer tissue, suggesting that the specific stimulating effect of the pDC-derived factor on NF- $\mathrm{KB}$ activation and subsequent CXCR-4 overexpression may be partly mediated through TNF-a secretion. TNF- $\alpha$ is reported to directly activate NF- $\mathrm{KB}$ pathways through the stimulation of TNF receptors [39]. Simultaneously, blocking TNF- $\alpha$ in the tumor microenvironment significantly down-regulates NF- $\mathrm{kB}$ activity and reduces cancer cell proliferation and invasion in breast cancer [40]. To further support our hypothesis, we showed that direct TNF-a stimulation upregulates CXCR-4 expression in an oral cancer Cal 27 cell line via NF- $\mathrm{kB}$ activation, and addition of TNF- $\alpha$ neutralizing antibodies could decrease the pDC-CMmediated NF-KB activation. Therefore, we speculated that pDC-derived TNF-a contributed in part, along with other inflammatory mediators in the tumor microenvironment, to activate the NF-kB pathway.

In conclusion, our data provide strong evidence that impaired tumor-infiltrating pDC are a strong predictor for LN metastasis in oral cancer, and that increased tumor-infiltrating $\mathrm{pDC}$ contributes to upregulation of CXCR-4 expression, possibly through TNF-a-mediated NF- $\mathrm{kB}$ activation, which ultimately leads to cell proliferation and migration toward LN via the CXCR4/SDF-1 chemoattraction axis. These data support the notion that crosstalk between tumor cells and tumor-infiltrating immune cells is critical for cancer development and metastasis. Careful manipulation of these impaired tumor-infiltrating pDC may help develop an important alternative immunotherapy for oral cancer.

\section{Supplementary Material}

Supplementary figures and tables.

http://www.jcancer.org/v12p3045s1.pdf

\section{Acknowledgements}

\section{Ethics approval and consent to participate}

This study was approved by the Shanghai Ninth People's Hospital IRB and informed signed consent was obtained from each patient.

\section{Funding}

This study was supported by the National Natural Science Foundation of China (Grant Number 81772870; 81472517), Health and Family Planning Commission Research Fund of Shanghai Municipality (Grant Number 201740186), Clinical Diagnosis and Treatment Center Construction Project of Fengxian District ( Grant Number (2017) 118 ), and Science and Technology Development Fund of Shanghai Fengxian District Science and Technology Commission (Grant Number 20170702 ).

\section{Authors' contributions}

$\mathrm{NNH}, \mathrm{XL}$ performed the experiments and analyzed the data. ZZ and MR designed the study. YPW and LW are responsible for the acquisition and interpretation of data. Statistical analysis was performed by CYZ. CPZ supervised the project.

\section{Availability of data and materials}

The datasets and materials used during the current study are available from the corresponding author on reasonable request.

\section{Competing Interests}

The authors have declared that no competing interest exists. 


\section{References}

1. Chi ACD TA, Neville BW: Oral cavity and oropharyngeal squamous cell carcinoma - an update. CA Cancer J Clin. 2015; 65(5):401-421.

2. Rebecca L. Siegel KDM, Ahmedin Jemal: Cancer statistics. CA Cancer J Clin. 2019; 69:7-34.

3. Ahmedin Jemal RS, Elizabeth Ward, Taylor Murray, Jiaquan Xu, Carol Smigal, Michael J. Thun: Cancer Statistics, 2006. CA: A Cancer Journal for Clinicians. 2006; 56:106-130.

4. Bindea G, Mlecnik B, Tosolini M, Kirilovsky A, Waldner M, Obenauf AC, Angell H, Fredriksen T, Lafontaine L, Berger A et al: Spatiotemporal dynamics of intratumoral immune cells reveal the immune landscape in human cancer. Immunity. 2013; 39(4):782-795.

5. Fridman WH, Zitvogel L, Sautes-Fridman C, Kroemer G: The immune contexture in cancer prognosis and treatment. Nat Rev Clin Oncol. 2017; 14(12):717-734

6. Robert D. Schreiber LJO, Mark J. Smyth: Cancer Immunoediting: Integrating Immunity's Roles in Cancer Suppression and Promotion Science. 2011; 331(6024):1565-1570.

7. Fridman WH, Galon J, Pages F, Tartour E, Sautes-Fridman C, Kroemer G: Prognostic and predictive impact of intra- and peritumoral immune infiltrates. Cancer Res. 2011; 71(17):5601-5605.

8. Fridman WH, Pages F, Sautes-Fridman C, Galon J: The immune contexture in human tumours: impact on clinical outcome. Nat Rev Cancer. 2012; 12(4):298-306

9. Gooden MJ dBG, Leffers N, Daemen T, Nijman HW The prognostic influence of tumour-infiltrating lymphocytes in cancer: a systematic review with meta-analysis. Br J Cancer. 2011; 105(1):93-103.

10. Li B, Li T, Pignon JC, Wang B, Wang J, Shukla SA, Dou R, Chen Q, Hodi FS, Choueiri TK et al: Landscape of tumor-infiltrating T cell repertoire of human cancers. Nat Genet. 2016; 48(7):725-732.

11. Vignali DA, Collison LW, Workman CJ: How regulatory T cells work. Nat Rev Immunol. 2008; 8(7):523-532.

12. Worbs T, Hammerschmidt SI, Forster R: Dendritic cell migration in health and disease. Nat Rev Immunol. 2017; 17(1):30-48

13. Ma Y, Shurin GV, Peiyuan Z, Shurin MR: Dendritic cells in the cancer microenvironment. J Cancer. 2013; 4(1):36-44.

14. Koucky V, Boucek J, Fialova A: Immunology of Plasmacytoid Dendritic Cells in Solid Tumors: A Brief Review. Cancers (Basel). 2019;11(4):470.

15. Swiecki M, Colonna M: The multifaceted biology of plasmacytoid dendritic cells. Nat Rev Immunol. 2015; 15(8):471-485.

16. Sisirak V, Faget J, Gobert M, Goutagny N, Vey N, Treilleux I, Renaudineau S, Poyet G, Labidi-Galy SI, Goddard-Leon $\mathrm{S}$ et al: Impaired IFN-alpha production by plasmacytoid dendritic cells favors regulatory T-cell expansion that may contribute to breast cancer progression. Cancer Res. 2012;72(20):5188-5197.

17. Faget J, Sisirak V, Blay JY, Caux C, Bendriss-Vermare N, Menetrier-Caux C: ICOS is associated with poor prognosis in breast cancer as it promotes the amplification of immunosuppressive CD4(+) T cells by plasmacytoid dendritic cells. Oncoimmunology. 2013; 2(3):e23185.

18. Labidi-Galy SI, Treilleux I, Goddard-Leon S, Combes JD, Blay JY, Ray-Coquard I, Caux C, Bendriss-Vermare N: Plasmacytoid dendritic cells infiltrating ovarian cancer are associated with poor prognosis. Oncoimmunology. 2012; 1(3):380-382

19. Han N, Zhang Z, Liu S, Ow A, Ruan M, Yang W, Zhang C: Increased tumor-infiltrating plasmacytoid dendritic cells predicts poor prognosis in oral squamous cell carcinoma. Arch Oral Biol. 2017; 78:129-134.

20. Han N, Zhang Z, Jv H, Hu J, Ruan M, Zhang C: Culture supernatants of oral cancer cells induce impaired IFN-alpha production of pDCs partly through the down-regulation of TLR-9 expression. Arch Oral Biol. 2018; 93:141-148.

21. Hartmann E WB, Rothenfusser S, Wagner M, Wellisch D, Mack B, Giese T, Gires O, Endres S, Hartmann G.: Identification and functional analysis of tumor-infiltrating plasmacytoid dendritic cells in head and neck cancer. Cancer Res. 2003; 63(19):6478-6487.

22. Lee JI JB, Kim MA, Yoon HJ, Hong SP, Hong SD: Prognostic significance of CXCR-4 expression in oral squamous cell carcinoma. Oral Surg Oral Med Oral Pathol Oral Radiol Endod. 2009; 107(5):678-684.

23. Reichert TE SC, Day R, Wagner W, Whiteside TL: The number of intratumoral dendritic cells and zeta-chain expression in T cells as prognostic and survival biomarkers in patients with oral carcinoma. Cancer. 2001; 91(11):2136-2147.

24. Goto $M$, Yoshida $T$, Yamamoto $Y$, Furukita $Y$, Inoue S, Fujiwara S, Kawakita N, Nishino T, Minato T, Yuasa Y, Yamai H, Takechi H, Seike J, Bando Y, Tangoku A: CXCR4 Expression is Associated with Poor Prognosis in Patients with Esophageal Squamous Cell Carcinoma. Ann Surg Oncol. 2017; 24(3):832-840

25. Wang J, Li D, Cang H, Guo B: Crosstalk between cancer and immune cells: Role of tumor-associated macrophages in the tumor microenvironment. Cancer Med. 2019; p:4709-4721.

26. Nagarsheth N, Wicha MS, Zou W: Chemokines in the cancer microenvironment and their relevance in cancer immunotherapy. Nat Rev Immunol. 2017; 17(9):559-572.

27. Kitamura T, Qian BZ, Pollard JW: Immune cell promotion of metastasis. Nat Rev Immunol. 2015; 15(2):73-86

28. Bogenrieder $\mathrm{T}$, Herlyn M: Axis of evil: molecular mechanisms of cancer metastasis. Oncogene. 2003; 22(42):6524-6536.
29. Gadalla R, Hassan H, Ibrahim SA, Abdullah MS, Gaballah A, Greve B, El-Deeb S, El-Shinawi M, Mohamed MM: Tumor microenvironmental plasmacytoid dendritic cells contribute to breast cancer lymph node metastasis via CXCR4/SDF-1 axis. Breast Cancer Res Treat. 2019; 174(3):679-691.

30. Chatterjee S, Behnam Azad B, Nimmagadda S: The intricate role of CXCR4 in cancer. Adv Cancer Res. 2014; 124:31-82.

31. Hung CS SH, Liang HH, Lai CW, Chang YC, Ho YS, Wu CH, Ho JD, Wei PL, Chang YJ: High-level expression of CXCR4 in breast cancer is associated with early distant and bone metastases. Tumour Bio. 2014; 35(2):1581-1588.

32. Hayakawa J MM, Ueda T, Fukazawa R, Adachi K, Ooue Y, Hayakawa M, Shimada T, Fukunaga Y: Dextran sulfate and stromal cell derived factor-1 promote CXCR4 expression and improve bone marrow homing efficiency of infused hematopoietic stem cells. J Nippon Med Sch. 2009; 76(4):198-208.

33. TOHRU ISHIKAWA K-IN, SHINGO HARA, SEBASTIAN K KLOSEK, CHUNNAN LI, SATORU SHINTANI, HIROYUKI HAMAKAWA: CXCR4 expression is associated with lymph-node metastasis of oral squamous cell carcinoma. INTERNATIONAL JOURNAL OF ONCOLOGY. 2006; p:2861-66.

34. Uchida D, Onoue T, Tomizuka Y, Begum NM, Miwa Y, Yoshida H, Sato M: Involvement of an autocrine stromal cell derived factor-1/CXCR4 system on the distant metastasis of human oral squamous cell carcinoma. Mol Cancer Res. 2007; 5(7):685-694.

35. Busillo JM BJ: Regulation of CXCR4 signaling. Biochim Biophys Acta. 2007; 1768(4):952-963.

36. Helbig G, Christopherson KW, 2nd, Bhat-Nakshatri P, Kumar S, Kishimoto $\mathrm{H}$, Miller KD, Broxmeyer HE, Nakshatri H: NF-kappaB promotes breast cancer cell migration and metastasis by inducing the expression of the chemokine receptor CXCR4. J Biol Chem. 2003; 278(24):21631-21638.

37. Ali A, Kim SH, Kim MJ, Choi MY, Kang SS, Cho GJ, Kim YS, Choi JY, Choi WS: O-GlcNAcylation of NF-kappaB Promotes Lung Metastasis of Cervical Cancer Cells via Upregulation of CXCR4 Expression. Mol Cells. 2017; 40(7):476-484.

38. Vallabhapurapu S, Karin M: Regulation and function of NF-kappaB transcription factors in the immune system. Annu Rev Immunol. 2009;27:693-733.

39. Liu S, Shi L, Wang Y, Ye D, Ju H, Ma H, Yang W, Wang Y, Hu J, Deng J et al: Stabilization of Slug by NF-kappaB is essential for TNF-alpha-induced Migration and Epithelial-Mesenchymal Transition in Head and Neck Squamous Cell Carcinoma Cells. Cell Physiol Biochem. 2018; 47(2):567-578.

40. Guo S, Deng CX: Effect of Stromal Cells in Tumor Microenvironment on Metastasis Initiation. Int J Biol Sci. 2018; 14(14):2083-2093. 